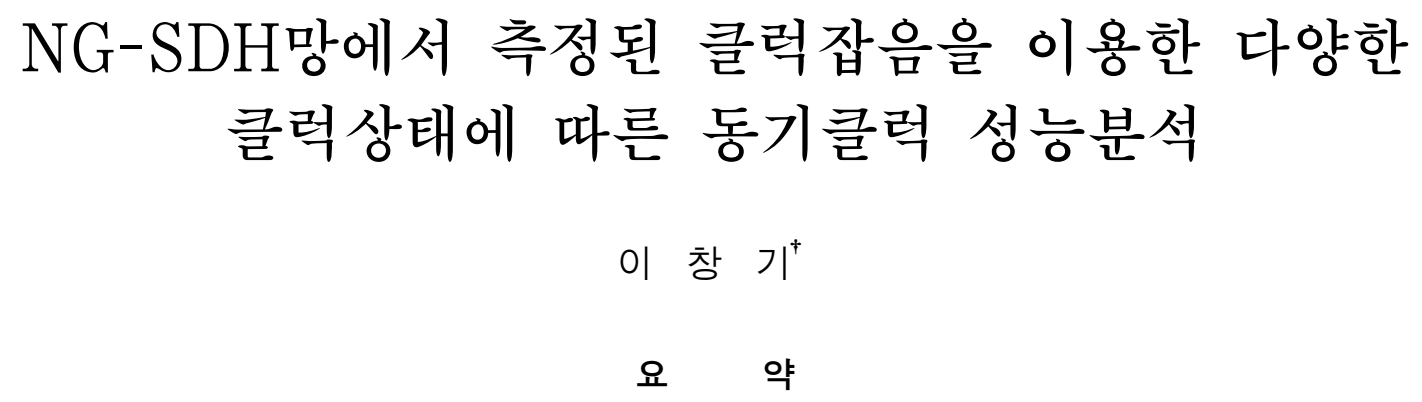

\begin{abstract}
$\mathrm{NG}-\mathrm{SDH}$ 망에서 측정된 클럭잡음을 이용한 동기클럭 성능분석 연구가 필요하다. 따라서 본 논문은 NG-SDH망에서 측정된 클럭잡음을 이용 하여 다양한 클럭상태에 따른 동기클럭 성능을 분석하고 최대 망노드수를 도출하기 위한 연구를 수행하였다. 또한 측정된 클럭잡음을 이용하여 적합한 클럭잡음모델을 생성하였고, 다양한 클럭상태에 따른 시뮬레이션을 수행하였다. 시뮬레이션 결과를 통해 볼 때 정상상태에서 최대노드 수는 80 개 노드 이상 이였고, 단기위상변위(SPT)상태에서는 37 개 이하였고, 장기위상변위(LPT)상태에서는 50 개 이상으로 나타났다. 따라서 3 가 지 클럭상태에서 ITU-T 규격을 만족할 수 있는 최대 노드수는 37개 이하 임을 알았다. 또한 DOTS 이전의 NE망에서 SPT이나 LPT상태가 발 생하면 정상상태의 안정된 다른 동기원 소스로 절체해야 함을 알았다.
\end{abstract}

키워드 : 동기클럭, 클럭잡음, 차세대 동기식전송

\title{
Performance Analysis of Synchronization Clock with Various Clock States Using Measured Clock Noises in NG-SDH Networks
}

\author{
Chang Ki Lee
}

\begin{abstract}
A study about performance analysis of synchronization clock using measured clock noises is required. Therefore this paper executed the study for performance analysis of synchronization clock and acquirement of maximum number of network node with various clock states using measured clock noises in NG-SDH networks. Also this paper generated a suitable clock model using measured clock noises, and carried out simulations with various clock states. Through the simulation results, maximum numbers were 80 or more network nodes in normal state, and were below 37 nodes in short-term phase transient(SPT) state, and were 50 or more in long-term phase transient(LPT) state. Accordingly this study showed that maximum numbers to meet ITU-T specification were below 37 network nodes in three clock states. Also this study showed that when SPT or LPT states occur from NE network before DOTS system, synchronization source must change with other stable synchronization source of normal state.
\end{abstract}

Keywords : Synchronization Clock, Clock Noise, NG-SDH

\section{1. 서 론}

NG-SDH(Next Generation-Synchronous Digital Hierarchy) $[1,2]$ 는 기존 $\mathrm{SDH}$ 기능과 함께 $\mathrm{EOS}($ Ethernet over $\mathrm{SDH})$, GFP(Generic Framing Procedure)[3], 가상연접(Virtual Concatenation)[2] 및 LCAS(Link Capacity Adjustment Scheme) [4] 기능들을 수행할 수 있는 차세대 전송기술을 말한다. $\mathrm{NG}-\mathrm{SDH}$ 에서는 초고속 신호를 전송함에 따라 동기클럭 성 능이 매우 중요하고, 또한 망노드를 거치면 클럭잡음 $[5,11]$

\footnotetext{
※ 이 연구결과물은 2008학년도 위덕대학교 학술진흥연구비 지원에 의하여 이 루어 졌음.

† 정 회 원 : 위덕대학교 정보통신공학과 부교수

논문접수: 2009년 5월 14일

수 정 일 : 1 차 2009 년 8 월 21 일

심사완료 : 2009년 8월 26일
}

이 누적되기 때문에 전송망을 설계할 때 클럭성능의 분석이 필요하다. 또한 $\mathrm{NG}-\mathrm{SDH}$ 시스템에서 발생할 수 있는 동기 클럭 상태[5-8]는 정상상태(NOR)와 단기위상변위상태인 short-term phase transient(SPT)상태, 장기위상변위상태인 long-term phase transient(LPT)상태로 나타날 수 있다. 이 와 같은 클럭상태는 클럭성능을 변화시켜 전송망 성능에 심 각한 영향을 줄 수 있어서 다양한 동기클럭 상태에 따른 동 기클럭 성능연구[14-17]도 요구되고 있다. 이에 따라 ITU-T에서는 동기클럭 규격[5-8]을 최근 보완하여 권고하 고 있어서 $\mathrm{SDH}$ 시스템과 함께 $\mathrm{NG}-\mathrm{SDH}$ 시스템도 이를 만 족하여야 한다. 그리고 클럭잡음의 누적에 직접적으로 영향 을 줄 수 있는 원더생성[5-12, 14-17] 성분을 실제로 망에서 측정한 자료가 있다면 전송망 구성에 따른 클럭성능을 분석 
하고 망구성 노드수을 결정하는데 매우 중요한 자료로 활용 할 수 있다. 지금까지의 연구를 살펴보면 Lucent, Mintera, 지멘스등 기타 선진국가 유수 기업에서는 현재 수십에서 수 백 $\mathrm{Gb} / \mathrm{s}$ 급 시스템을 개발하였거나 개발 중에 있지만 동기클 럭 기술에 관한 연구보고나 기술자료는 아직까지 공개되고 있지 않다. 또한 세계 각국에서 자국 동기망의 원더생성을 측정하여 이를 성능분석에 활용한 연구도 발표되지 않고 있 다. 국내에서는 현재 $\mathrm{ETRI}$ 에서 $\mathrm{NG}-\mathrm{SDH}$ 시스템에 대한 연 구개발이 진행 중에 있고, $\mathrm{NG}-\mathrm{SDH}$ 클럭특성에 관한 연구 는 다양한 클럭상태에 대한 연구[17]가 수행되었으나 실제로 망에서 측정한 데이터를 활용하여 수행하지 않고 클럭규격 에 근접한 클럭잡음 모델을 만들어서 연구가 이루어졌기 때 문에 국내 동기클럭에 대한 성능분석 연구가 제대로 수행되 지 못하였다. 그러나 최근 국내 전송망에서 실제 측정된 클 럭잡음 성분에 대한 연구결과[18]가 제시된 바 있다.

따라서 본 논문은 실제 측정된 클럭잡음 성분을 활용하여 클럭모델을 만들어서 $\mathrm{NG}-\mathrm{SDH}$ 망에서의 다양한 클럭상태에 따른 동기클럭 성능을 분석하고 이에 따른 최대 망노드수에 대한 연구를 수행하는 것이다. 상기 내용을 바탕으로 하여 $\mathrm{NG}-\mathrm{SDH}$ 동기기능과동기클럭 특성규격을 2장에서 기술하 고, 3 장에서는 측정된 클럭잡음을 활용하여 동기클럭 성능 시뮬레이션을 수행하여 얻은 결과를 기술하며, 4장에서는 마지막 결론으로 맺는다.

\section{NG-SDH 망의 동기클럭}

$\mathrm{NG}-\mathrm{SDH}$ 전송망의 망동기를 위해 공급되는 동기원은 국 내 최초 동기원 소스인 $\mathrm{KRF}$ (Korea Reference Frequency) 혹은 $\mathrm{PRC}($ Primary Reference Clock)를 중심으로 총괄국의 동기클럭 공급장치인 DOTS(Digital Office Timing Supply)1, 중심국의 DOTS2 등으로 구성되어있다. (그림 1) 에서 $\mathrm{KRF}(\mathrm{PRC})$ 에서 제공되는 동기원은 분배망을 통해 $\mathrm{DOTS}[13]$ 에 공급되고, DOTS는 $\mathrm{KRF}$ 에 동기된 동기클럭을 생성하여 동일 계층내 모든 전송망에 공급함으로써 $\mathrm{KRF}$ 기 준 망동기가 실현된다. 그러나 $\mathrm{KRF}$ 클럭은 분배망[16]을 거 치는 동안에 망요소들의 자체 잡음[15]인 원더생성과 지터 등이 누적됨에 따라 실제 전송망의 동기원으로 제공되는 동 기클럭 성능은 $\mathrm{KRF}$ 고유의 성능보다 저하되어 나타난다. 이에 따라 $\mathrm{KRF}$ 와 $\mathrm{DOTS}$, 그리고 분배망이나 전송망의 노

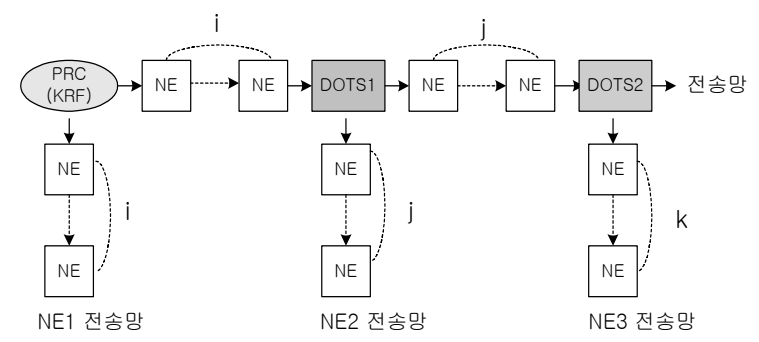

(그림 1) 동기클럭 분배망의 구조
드인 $\mathrm{NE}$ (network element)에서 자체적으로 발생되는 원더 생성과 출력클럭의 단기안정도를 규격으로 규정하여 제한하 고 있다. (그림 1)에서 $\mathrm{KRF}$ 를 동기원으로 하는 전송망을 $\mathrm{NE} 1, \mathrm{DOTS} 1$ 을 동기원으로 하는 전송망을 $\mathrm{NE} 2, \mathrm{DOTS} 2$ 를 동기원으로 하는 전송망을 $\mathrm{NE3}$ 이라 한다.

동기클럭의 성능을 비교하고 특성을 이해하기 위해서는 전송망 노드에서 성능을 측정해야 하지만 이들을 일일이 측 정하기 어렵기 때문에 동기클럭 모델을 이용하여 시뮬레이 션을 통해서 성능을 예측해야한다. ITU-T에서 권고하고 있 는 동기클럭의 수학적 모델[5, 12]에서 클럭의 특성변화는 이상적인 클럭신호와 실제의 클럭신호 간의 시간적인 편차 로 나타내고 있다. 주어진 클럭의 시간함수 $T(t)$ 와 이상적 인 시간함수 $T_{r e f}(t)$ 사이의 시간오차 $x(t)$ 는 (1)식과 같이 쓸 수 있다. 여기서 $x_{0}$ 는 초기 시간오차 옵셋이며, $f_{0}$ 는 클럭의 기준 주파수, $y_{0}$ 는 초기 주파수 변동 성분, $D$ 는 주 파수 표류(drift)율이며, $\phi(t)$ 는 랜덤 위상편차를 나타낸다.

$$
x(t)=T(t)-T_{r e f}(t)=x_{0}+y_{0} t+\frac{D}{2} t^{2}+\frac{\varphi(t)}{2 \pi f_{0}}
$$

정규화된 주파수 변동(frequency fluctuation) $y(t)$ 는 (2) 식과 같이 시간오차 함수를 미분함으로써 얻을 수 있다

$$
y(t)=\frac{f(t)-f_{o}}{f_{o}}=\frac{1}{2 \pi f_{o}} \frac{d \Phi(t)}{d t}=\frac{d x(t)}{d t}
$$

클럭모델에 직접적으로 이용하는 (1)식에서 $y_{0}$ 와 $D$ 는 규정될 수 있는 성분이지만 랜덤 위상편차인 $\phi(t)$ 는 랜덤 한 성분이기 때문에 클럭에서 나타나고 있는 다양한 잡음성 분[14]을 적용해서 클럭의 시간오차 모델을 생성해야한다.

동기망과 전송망에 적용되는 중요한 클럭규격은 최초 클 럭소스인 $\mathrm{PRC}$ 혹은 $\mathrm{KRF}(\mathrm{G} .811)[6]$ 와 동기클럭 공급장치인 $\operatorname{DOTS}(\mathrm{G} .812)[7]$, 그리고 전송망 노드장치인 $\mathrm{NE}(\mathrm{G} .813)$ [8]에 관한 규격이며, 장치 입출력규격과 장치 내부에서만 발생되 는 클럭잡음 성분인 원더생성 $[5,14]$ 으로 구분된다. 장치출력 클럭은 클럭상태에 따라 정상상태(NOR), SPT상태, LPT상 태 $[5,17]$ 로 나누어서 규격을 권고하고 있다. 정상상태는 동 기원에 의해 정상적인 동기기능이 수행되는 상태를 말하고, $\mathrm{SPT}$ 상태는 동기원 장애로 인해 클럭절체 때 발생되는 15 초 이내의 위상변위상태를 말하고, LPT상태는 모든 동기원에 장애가 발생하여 홀드오버 상태가 15초 이상 지속되는 위상 변위상태를 말한다. 여기서 본 논문에서는 ITU에서 권고하 고 있는 다양한 규격 중 국내에서 적용되고 있는 G.812의 TYPE I과 G.813의 option 1만을 고려하였고, PRC는 SPT와 $\mathrm{LPT}$ 상태가 적용되지 않는다. ITU에서 권고하고 있는 규격 은 $\mathrm{SDH}$ 와 $\mathrm{NG}-\mathrm{SDH}$ 의 모든망에서 공히 만족해야 하고, 클 럭의 단기안정특성을 나타내고 있는 MTIE(maximum time interval error)[5,12,14]와 $\mathrm{TDEV}$ (time deviation)[5, 12, 14]의 
성능측정지수를 사용하며, $\mathrm{MTIE}$ 와 $\mathrm{TDEV}$ 의 정의식[5, 12] 은 아래와 같다.

$$
\begin{aligned}
& \operatorname{MTIE}\left(n \tau_{0}\right)=\begin{array}{c}
N-n \\
\max \\
k=1
\end{array}\left[\begin{array}{lc}
k+n & k+n \\
\max & x_{i}-\min _{i=k} \\
i=k & x_{i}
\end{array}\right]
\end{aligned}
$$

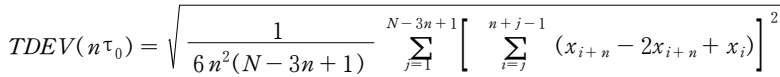

\section{3. 동기클럭 성능시뮬레이션}

\section{1 측정된 클럭잡음과 생성된 클럭잡음}

$\mathrm{NG}-\mathrm{SDH}$ 망의 동기클럭 성능시뮬레이션에 적합한 망 토 폴로지는 선형망[14, 16]이며, 클럭잡음이 누적되는 다단연결 형태와 동기원 특성, 전송노드 수, 클럭상태 등 최악의 출력 클럭 특성이 나타날 수 있기 때문이다. 선형망으로 구성된 $\mathrm{NG}-\mathrm{SDH}$ 전송망의 모델 $[14,16]$ 을 수식으로 표현하면 (5)식 으로 표현할 수 있고, 동기망은 (6)식으로 표현된다.

$$
\begin{gathered}
N_{O}^{(k)}(s)=\left(H_{1}(s)\right)^{k} N_{I N}(s)+\sum_{n=1}^{k}\left(H_{1}(s)\right)^{k-n}\left[N_{W G}^{(n)}(s)+N_{P T}^{(n)}(s)\right] \\
D T_{O}(s)=H_{2}(s) N_{s}(s)+D T_{W G}(s)+D T_{P T}(s)
\end{gathered}
$$

여기서 $N \stackrel{(k)}{O}(s)$ 는 $k$ 번째 노드에서의 출력클럭잡음이고, $N_{I N}(s)$ 는 첫 번째 노드로 입력되는 입력클럭잡음이다. 또 한 $H_{1}(s)$ 는 노드의 저역 통과필터 전달함수, $N_{W G}^{(n)}(s)$ 는 $n$ 번째 노드의 원더생성, 그리고 $N_{P T}^{(n)}(s)$ 는 $\mathrm{n}$ 번째 노드의 단 기 및 장기위상변위성분이다. 그리고 $D T_{O}(s)$ 는 DOTS에서 출력되는 동기원특성이고, $D T_{P T}(s)$ 와 $D T_{W G}(s)$ 는 DOTS 의 위상변위성분과 원더생성이고 $N_{S}(s)$ 는 DOTS로 입력 되는 동기클럭이다. 여기서 망의 입력 동기원인 $N_{I N}(s)$ $[16,18]$ 와 원더생성과 클럭상태만 결정되면 $\mathrm{NG}^{-} \mathrm{SDH}$ 망노 드의 클럭특성을 알 수 있다.

실제 전송망과 동기망에서 측정된 원더생성성분[18]은 (그림 2)에 나타내었으며, 각 그림의 X축은 $\mathrm{MTIE}$ 와 $\mathrm{TDEV}$ 를 계산할 때 사용되는 관측시간 $(\mathrm{sec})$ 이고, $\mathrm{Y}$ 축은 각 관측시 간 별로 계산하여 얻어진 (3)식의 MTIE와 (4)식의 TDEV 값을 나타내고 있다. 이와 같은 $\mathrm{X}, \mathrm{Y}$ 축의 내용은 본 논문에 서 사용하고 있는 모든 특성그림에 똑같이 적용된다. (그림 2)(a)는 PRC클럭의 원더생성에 대한 MTIE와 TDEV특성이 다. 여기서 실선은 G.811의 MTIE와 TDEV 특성규격이고, 'X'는 실제 측정된 $\mathrm{MTIE}$ (윗쪽)와 $\mathrm{TDEV}$ (아래쪽) 특성값이 며, ' $\mathrm{O}$ '는 실제 측정값을 토대로하여 본 논문에서 만든 클럭 모델의 $\mathrm{MTIE}$ (위)와 $\mathrm{TDEV}$ (아래) 특성값이다. 클럭모델[14]

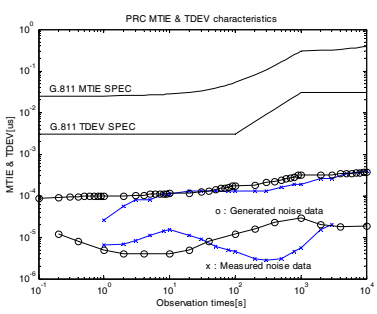

(a) PRC 원더생성

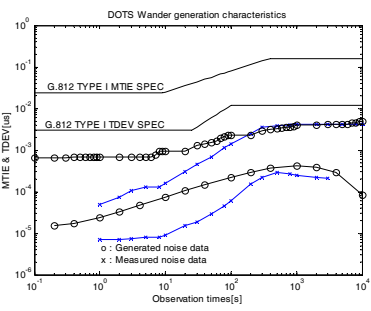

(b) DOTS 원더생성

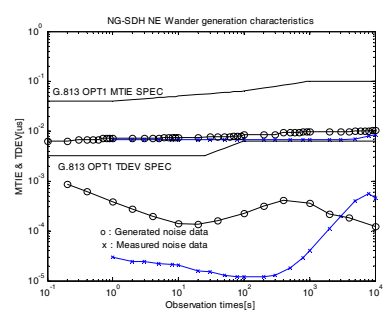

(c) $\mathrm{NE}$ 원더생성

(그림 2) 실제 측정된 원더생성 성분

은 백색위상잡음(WPM), 플리커위상잡음(FPM), 백색주파수 잡음 $(\mathrm{WFM})$ 을 이용하여 생성하였다. 클럭잡음 모델을 생성 할 때 랜덤데이터를 이용하기 때문에 여러번 시물레이션을 수행하여 실제 모델에 최대한 근접한 데이터를 얻어야 한 다. 그리고 $\mathrm{TDEV}$ 특성 보다 좀더 민감하게 나타나는 $\mathrm{MTIE}$ 특성에 근접하도록 생성해야했기 때문에 실제측정치와는 다 소 차이가 있음을 보이고 있다. (그림 2)(b)와 (c)는 DOTS 와 $\mathrm{NE}$ 에서 실제 측정된 원더생성 성분을 이용하여 만든 $\mathrm{MTIE}$ 와 TDEV 클럭잡음 특성(' $\left.\mathrm{O}^{\prime}\right)$ 이다. (c)에서 아래쪽 $\mathrm{TDEV}$ 특성이 실제측정값과 다소 차이가 나는 것은 $\mathrm{MTIE}$ 중심으로 맞추다보니 $\mathrm{TDEV}$ 특성은 다소 차이가 나고 있다. 그러나 $\mathrm{TDEV}$ 특성은 실제 최대노드수의 도출에 영향을 크 게 주지 않기 때문에 생성된 모델을 그대로 사용하였다. 시 뮬레이션에 적용되는 노드수는 $\mathrm{NE}$ 망에 따라 $i, j$ 및 $k$ 로 적 용된다. (그림 1)에서 만일 $\mathrm{PRC}$ (혹은 $\mathrm{KRF}$ )를 동기원으로 하는 선형 $\mathrm{NG-SDH}$ 망 $(\mathrm{NE} 1)$ 이 있다면 선형전송망의 노드수 가 $i$ 가 되고, 만일 전송망이 DOTS1에서 오는 동기원을 사 용할 경우(NE2)에는 $\mathrm{PRC}$ 에서 DOTS1까지의 노드수가 $i$ 가 되고, 선형전송망의 노드수는 $j$ 가 된다. DOTS2를 동기원으 로 하는 전송망 $(\mathrm{NE} 3)$ 은 $\mathrm{PRC}$ 에서 $\mathrm{DOTS} 1$ 까지의 노드수가 $i$, $\mathrm{DOTS} 1$ 에서 DOTS2까지의 노드수가 $j, \mathrm{DOTS} 2$ 클럭을 동기 원으로 하여 구성된 전송망의 노드수가 $k$ 로 적용된다. 클럭 상태는 정상상태, SPT상태와 LPT상태를 사용하여 $\mathrm{NE}$ 와 DOTS에 모두 적용하여 시뮬레이션을 수행하였다. 그리고 DOTS와 NE의 차단주파수는 각각 $0.1 \mathrm{~Hz}, 1 \mathrm{~Hz}$ 로 사용하였 고, 클럭 비트레이트는 선로신호인 $40 \mathrm{Gbps}$ 를 사용하였다. 시뮬레이션은 실제 측정된 클럭잡음을 기반으로 만든 원더 생성성분을 $\mathrm{PRC}, \mathrm{DOTS}, \mathrm{NE}$ 에 각각 적용한 후 노드수를 증가하면서 얻어진 $\mathrm{NE}$ 특성이 규격치와 만족여부를 조사하 면서 수행하였으며, 이를 통하여 규격 만족하는 망 최대 노 드수 결과를 얻을 수 있다. 


\section{2 정상상태 시뮬레이션}

3.1절에서 실제 측정된 클럭잡음을 이용하여 생성된 클럭 잡음 모델을 정상상태로 적용하여 동기클럭 특성시뮬레이 션을 NE1, NE2, NE3 별로 수행하였다. 시뮬레이션 결과는 (그림 3)에 나타내었다. (그림 3)(a)는 $\mathrm{PRC}$ 를 동기원으로 사 용하는 $\mathrm{NE} 1$ 에서 $i$ 가 $40\left(^{\prime} \mathrm{O}^{\prime}\right), 80\left(^{\prime}+^{\prime}\right), 99\left({ }^{\prime} \mathrm{x}^{\prime}\right)$ 일 때의 노드클 럭 $\operatorname{MTIE}($ 위 $)$ 및 $\mathrm{TDEV}$ (아래) 특성이며, 모든 관측시간에서 얻어진 MTIE와 TDEV 값은 G.813의 출력규격보다 크게 못 미칠 정도의 낮은 값을 가지는 매우 좋은 클럭특성을 보이 고 있다. (그림 3)(b)는 $i$ 가 20인 DOTS1 동기원을 사용하여 $j$ 가 20('o'), 40('+'), $80\left({ }^{\prime} \mathrm{X}^{\prime}\right)$ 일 때 $\mathrm{NE} 2$ 노드클럭 특성을 나 타낸 것으로 $\mathrm{MTIE}$ 와 $\mathrm{TDEV}$ 값 모두 관련규격을 만족하고 있다. (그림 3)(c)는 $i, j$ 가 20인 DOTS2 동기원을 사용하였 을 경우 $k$ 가 $20\left({ }^{\prime} \mathrm{O}^{\prime}\right), 40\left({ }^{\prime}+^{\prime}\right), 80\left({ }^{\prime} \mathrm{x}^{\prime}\right)$ 일 때의 $\mathrm{NE} 3$ 클럭특성 이며, 이 특성도 규격값보다 훨씬 좋은 MTIE와 TDEV값을 가지면서 관련규격을 만족하였다. (그림 2)(d)는 (a),(b),(c)에 서 노드수가 80 일 때를 모아서 비교하였고, 여기서 사용중 인 DOTS1과 DOTS2의 동기원 특성도 표시하였다. 노드수 가 증가함에 따라 클럭잡음이 누적되어 클럭특성이 나빠지 고 있는 것을 볼 수 있고, DOTS 특성에서도 DOTS2 동기 원이 DOTS1동기원보다 클럭특성이 클럭잡음의 누적에 따 라 특성이 좋지 않음을 볼 수 있다. 따라서 전반적으로 노 드수가 증가함에 따라, 즉 $i$ 보다 $j$ 가, $j$ 보다 $k$ 에서의 $\mathrm{NE}$ 노 드특성과 DOTS1보다 DOTS2 동기원 특성이 클럭잡음의 누적으로 점점 성능이 떨어지고 있음을 볼 수 있다. 그림으 로 표시하지 못한 나머지 경우를 포함하여 시률레이션을 수 행한 정상상태의 결과는 <표 1>에 나타내었다. <표 1>에서 $\mathrm{NE} 1$ 일 경우 $i$ 가 80 개 이상, $\mathrm{NE} 2$ 일 경우 $j$ 가 80 개 이상, $\mathrm{NE} 3$ 일 경우 $k$ 가 80 개 이상 노드에서도 $\mathrm{MTIE}$ 와 $\mathrm{TDEV}$ 관 련규격을 모두 만족하였고, 동기원인 DOTS1, DOTS2도 모

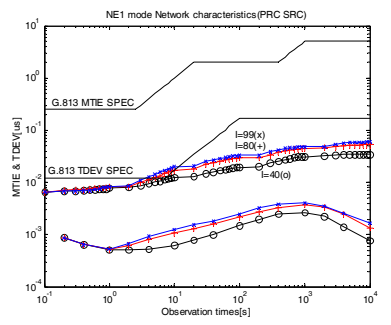

(a) i가 40, 80, 99인 NE1특성

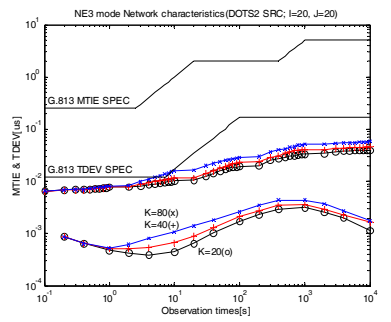

(c) $\mathrm{k}$ 가 20, 40, 80인 NE3특성

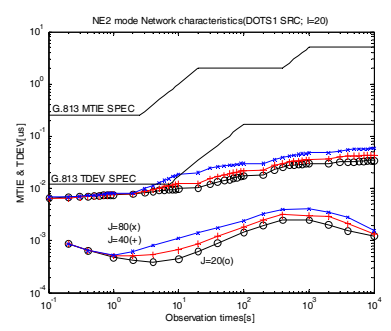

(b) j가 20, 40, 80인 NE2특성

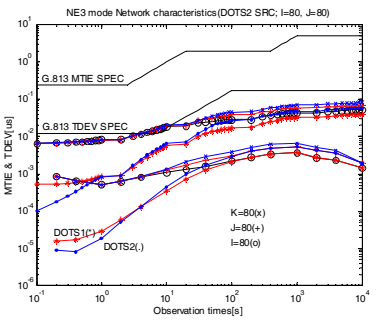

(d) NE와 DOTS 노드특성
(그림 3) 정상상태의 노드클럭특성
〈표 1〉정상상태에서의 노드수

\begin{tabular}{|c|c|c|c|}
\hline 형태 & NE1 & NE2 & NE3 \\
\hline \hline \multirow{2}{*}{ 동기원 } & \multirow{2}{*}{ PRC } & DOTS1 & DOTS2 \\
\cline { 3 - 4 } & & $\mathrm{i}=1,5,10,15,20$ & $\mathrm{i}, \mathrm{j}=1,5,10,15,20$ \\
\hline 노드수 & $80 \geq$ & $80 \geq$ & $80 \geq$ \\
\hline \multicolumn{2}{|l}{ 탠덤노드 규격만족도 } & $\begin{array}{c}\text { NE1/DOTS1 } \\
\text { NOR 규격 만족 }\end{array}$ & $\begin{array}{c}\text { NE1,2/DOTS1,2 } \\
\text { NOR 규격 만족 }\end{array}$ \\
\hline
\end{tabular}

두 G.812 동기원 규격을 만족하였다.

\subsection{SPT상태 시뮬레이션}

$\mathrm{SPT}$ 상태는 NE와 DOTS에서 각각 일어날 수 있으나 전 송망 중심으로 살펴보면 1) 최종단 전송망에만 $\mathrm{SPT}$ 상태가 발생하고 나머지 전송망은 정상상태가 되는 경우인 $\mathrm{NENS}$, 2) 최종단의 전송망과 DOTS만이 SPT 상태가 발생되고 나 머지의 이전단의 전송망과 DOTS가 정상상태인 경우를 $\mathrm{NENDS}$, 3) 모든 전송망에 SPT상태가 발생되고 DOTS는 정상상태인 경우를 $\mathrm{NSNS}$ 로 각각 나누어서 시률레이션을 수행하였다.

$\mathrm{NENS}$ 와 NENDS 경우에 대한 노드클럭 특성은 (그림 4) 에 나타내었다. (그림 4)(a)는 NE3에서 최종단 $k$ 개 노드로 이루어진 전송망에서 $\mathrm{SPT}$ 상태가 발생한 NENS로써, $i, j$ 가 20 이고, $k$ 가 35 와 38 일 때의 $\mathrm{MTIE}$ 와 TDEV 특성이며, $k$ 가 38 일 때 3,000 초의 관측시간에서 MTIE규격을 넘어섰다. (그림 4)(b)는 (a)경우에서 3,000 초에서 부근을 확대한 그래 프로, 3,000초에서 규격을 만족하지 못함('+')을 볼 수 있고, 또한 $i$ 가 1 인 $\mathrm{NE} 1$ 경우에도 $j$ 가 38 일 때 7,000 초의 관측시 간에서 규격을 만족하지 못하였고(' $\left.x^{\prime}\right), i, j$ 가 1 인 NE3 일 때 도 $k$ 가 38 개 노드에서 3,000 초의 관측시간에서 규격을 넘어 서고 있음('o')을 볼 수 있다. (그림 4$)(\mathrm{c})$ 는 $\mathrm{NE} 2(i=1)$ 와 $\mathrm{NE} 3(i, j=20)$ 일 경우 동기원클럭으로 사용되는 $\operatorname{DOTS} 1\left(\mathrm{x}^{\prime}\right)$

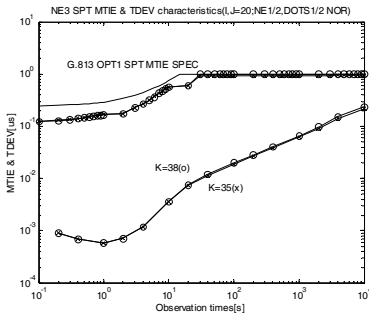

(a) i,j가 20일 때의 NENS특성

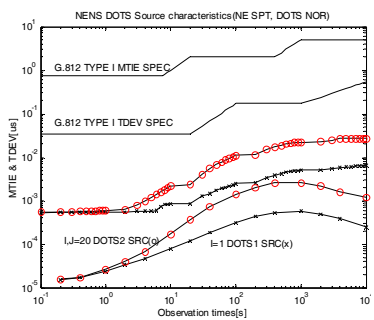

(c) NENS의 DOTS특성

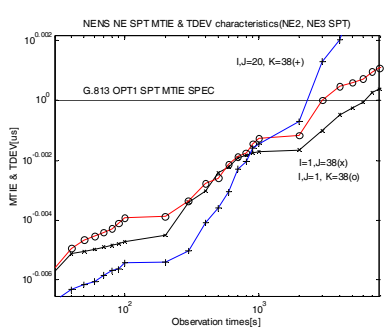

(b) (a)의 확대 그림

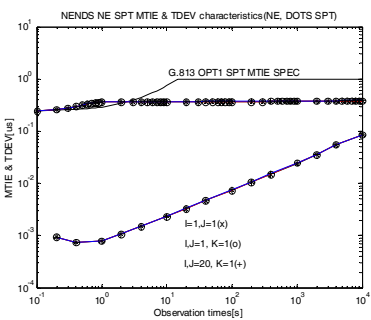

(d) NENDS NE특성
(그림 4) NENS, NENDS SPT상태의 노드클럭특성 
과 $\operatorname{DOTS2}\left({ }^{\prime} o^{\prime}\right)$ 의 $\operatorname{MTIE}$ (위), $\mathrm{TDEV}$ (아래) 클럭 특성을 관 련규격과 비교한 것으로, 모두 만족하고 있음을 볼 수 있다. $\mathrm{NENS}$ 의 나머지 NE1, NE2, NE3 노드수에 대한 시뮬레이션 결과는 <표 2>에 나타내었다. <표 2>에서 NE1, NE2, NE3 의 경우 모두 38 개 노드에서 관련 규격을 만족하지 못함을 볼 수 있다. 그러나 최종단이 아닌 중간 $\mathrm{NE}$ 노드클럭과 DOTS 동기원 클럭은 정상상태의 클럭규격을 모두 만족하 였다. 최종단 $\mathrm{NE}$ 와 DOTS가 동시에 $\mathrm{SPT}$ 상태가 발생한 NENDS 경우는 (그림 4)(d)에 나타내었다. $i$ 가 1 인 NE2('x') 일 때 $j$ 가 1 부터 관측시간 0.1 초에서 MTIE 규격을 만족치 못하였고, $i, j$ 가 $1\left({ }^{(} \mathrm{o}^{\prime}\right)$ 이거나 $i, j$ 가 $20\left({ }^{(}+{ }^{\prime}\right)$ 인 $\mathrm{NE} 3$ 경우에도 역시 $k$ 가 1 부터 관측시간 0.1 초에서 MTIE 규격을 넘어섰 다. 나머지 경우의 시뮬레이션 결과는 그래프가 많아서 <표 $3>$ 에 나타내었다. <표 $3>$ 에서 $i$ 와 $j$ 가 $1,5,10,15,20$ 등 다양한 중간 노드수에서도 최종노드수가 1 일 때부터 MTIE 규격을 만족치 못함을 볼 수 있다. 그러나 중간노드에서의 $\mathrm{NE}$ 와 DOTS 동기원 규격은 모두 만족하였다. 따라서 DOTS에서 SPT발생한 상태에서 다음단 NE도 SPT가 발생 하면 노드수 1 개부터 규격을 만족하지 않는다는 것을 알 수 있다.

모든 전송망을 SPT상태로 적용하는 NSNS의 노드클럭 특성은 (그림 5)에 나타내었다. (그림 5)(a)는 $i$ 가 1 이고, $j$ 가 5 와 10 일 때의 NE2 MTIE와 TDEV 특성이며, $j$ 가 10일 때 관측시간 5 초에서 SPT MTIE규격을 만족하지 않았고, (그림 5)(b)는 $i$ 가 20이고, $j$ 가 5, 7일 때의 클럭특성이며, $j$ 가 7 일 때부터 관측시간 4,000 초에서 MTIE규격을 만족하지 않았다. (그림 5)(c)는 $i, j$ 가 20이고, $k$ 가 1 일 때의 NE3 특 성으로 $k$ 가 1 일 때부터 관측시간 40초에서 $\mathrm{MTIE}$ 규격을 만 족하지 못하였다. (그림 5)(d)는 NE2와 NE3일 때 중간 노드 가 되는 NE1과 NE2의 SPT상태 출력이 SPT 규격 만족여 부를 살펴본 것이다. $i$ 가 1 일 때의 $\mathrm{NE1}$ 출력 특성 (' $\mathrm{x}$ ')과 $i, j$ 가 20일 때 NE2 출력특성('o') 살펴본 결과 $i, j$ 가 20일 때는

〈표 2〉NENS일 때의 노드수

\begin{tabular}{|c|c|c|c|}
\hline 형태 & $\begin{array}{l}\text { NE1 } \\
\text { (SPT) }\end{array}$ & NE2(SPT) & NE3(SPT) \\
\hline \multirow{2}{*}{ 동기원 } & \multirow{2}{*}{ PRC } & DOTS1(NOR) & DOTS2(NOR) \\
\hline & & $\mathrm{i}=1,5,10,15,20$ & $\mathrm{i}, \mathrm{j}=1,5,10,15,20$ \\
\hline 노드수 & 38 & 38 & 38 \\
\hline \multicolumn{2}{|c|}{$\begin{array}{c}\text { 탠덤노드 } \\
\text { 규격만족도 }\end{array}$} & $\begin{array}{c}\text { NE1/DOTS1 } \\
\text { NOR 규격 만족 }\end{array}$ & $\begin{array}{l}\text { NE1,2/DOTS1,2 } \\
\text { NOR 규격 만족 }\end{array}$ \\
\hline
\end{tabular}

〈표 3〉NENDS일 때의 노드수

\begin{tabular}{|c|c|c|c|}
\hline 형태 & $\begin{array}{l}\text { NE1 } \\
\text { (SPT) }\end{array}$ & NE2(SPT) & NE3(SPT) \\
\hline \multirow{2}{*}{ 동기원 } & \multirow{2}{*}{ PRC } & DOTS1(SPT) & DOTS2(SPT) \\
\hline & & $\mathrm{i}=1,5,10,15,20$ & $\mathrm{i}, \mathrm{j}=1,5,10,15,20$ \\
\hline 노드수 & 38 & 1 & 1 \\
\hline \multicolumn{2}{|c|}{$\begin{array}{l}\text { 탠덤노드 } \\
\text { 규격만족도 }\end{array}$} & $\begin{array}{c}\text { NE1 NOR, DOTS1 SPT } \\
\text { 규격 만족 }\end{array}$ & $\begin{array}{l}\text { NE1,2 NOR, DOTS1,2 } \\
\text { SPT 규격 만족 }\end{array}$ \\
\hline
\end{tabular}

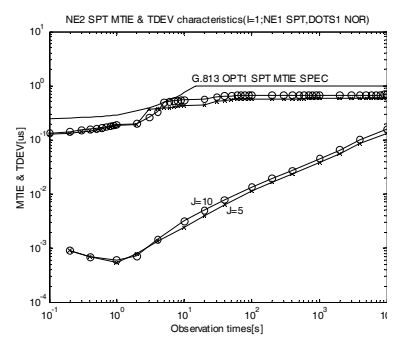

(a) j가 5, 10인 NE2 특성

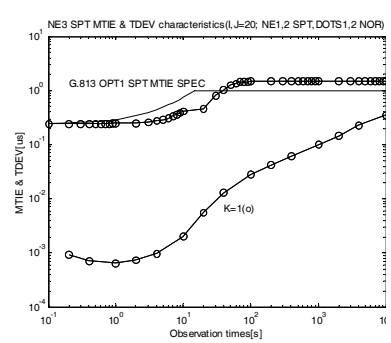

(c) $\mathrm{k}$ 가 1 인 NE3 특성

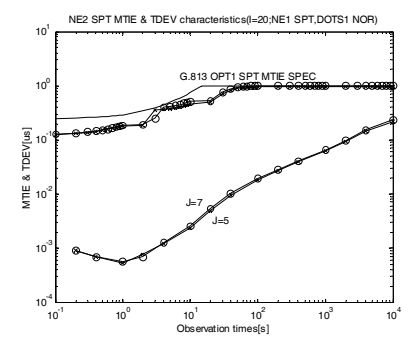

(b) j가 5, 7인 NE2 특성

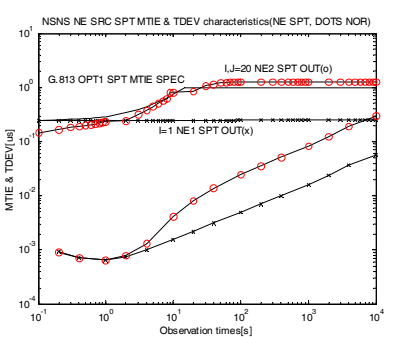

(d) NSNS 세부 NE노드 특성
(그림 5) NSNS SPT상태의 노드클럭특성

$\mathrm{NE}$ 로 가기전에 벌써 SPT MTIE 규격을 만족하지 못하였 다. NSNS의 나머지 경우에 대한 시뮬레이션 결과는 <표 $4>$ 에 나타내었다. <표 $4>$ 에서 NE1의 규격을 넘어서는 노 드수가 38 개에서 $\mathrm{NE} 2$ 일 경우 $i$ 가 증가할수록 $10,12,7$ 로 전체적으로 감소하였고, $\mathrm{NE} 3$ 일 경우는 10 개에서 1 개의 노드 수로 줄어들고 있음을 볼 수 있다. 그리고 중간(탠덤)노드의 성능은 (그림 5)(d)에서 살펴본 바와 같이 $i, j$ 가 15,20 일 때 SPT MTIE 규격을 만족하지 못하였고, 나머지의 경우는 모 두 관련규격을 만족하였다.

〈표 4〉NSNS일 때의 노드수

\begin{tabular}{|c|c|c|c|c|c|c|c|c|}
\hline 형태 & $\begin{array}{l}\text { NE1 } \\
\text { (SPT) }\end{array}$ & \multicolumn{3}{|c|}{ NE2(SPT) } & \multicolumn{4}{|c|}{ NE3(SPT) } \\
\hline \multirow{2}{*}{ 동기원 } & \multirow{2}{*}{ PRC } & \multicolumn{3}{|c|}{ DOTS1(NOR) } & \multicolumn{4}{|c|}{ DOTS2(NOR) } \\
\hline & & $\mathrm{i}=1,5$ & $\mathrm{i}=10,15$ & $\mathrm{i}=20$ & $i, j=1$ & $i, j=5$ & $\mathrm{i}, \mathrm{j}=10$ & $\mathrm{i}, \mathrm{j}=15,20$ \\
\hline 노드수 & 38 & 10 & 12 & 7 & 10 & 6 & 1 & 1 \\
\hline \multicolumn{2}{|c|}{$\begin{array}{l}\text { 탠덤노드 } \\
\text { 규격만족도 }\end{array}$} & \multicolumn{3}{|c|}{$\begin{array}{l}\text { NE1 SPT, DOTS1 } \\
\text { NOR 규격 만족 }\end{array}$} & \multicolumn{3}{|c|}{$\begin{array}{c}\text { NE1,2 SPT, } \\
\text { DOTS1,2 NOR } \\
\text { 규격만족 }\end{array}$} & $\begin{array}{l}\text { NE2 SPT } \\
\text { 불만족, 그 } \\
\text { 외 모두만족 }\end{array}$ \\
\hline
\end{tabular}

\subsection{LPT상태 시뮬레이션}

LPT 시률레이션도 SPT상태와 동일하게 1) 최종단 전송 망에만 LPT상태가 발생하고 나머지 전송망은 정상상태가 되는 경우인 NENL, 2) 최종단의 전송망과 DOTS만이 LPT 상태가 발생되고 나머지의 이전단의 전송망과 DOTS가 정 상상태인 경우를 NENDL, 3) 모든 전송망에 LPT상태가 발 생되고 DOTS는 정상상태인 경우를 NLNL로 각각 나누어 서 시뮬레이션을 수행하였다.

NENL, NENDL 경우에 대한 노드클럭 특성은 (그림 6)에 나타내었다. (그림 6)(a)는 NE2, NE3에서 최종단 전송망에 $\mathrm{LPT}$ 상태가 발생한 NENL에 대한 시뮬레이션 결과이다. $i$ 가 


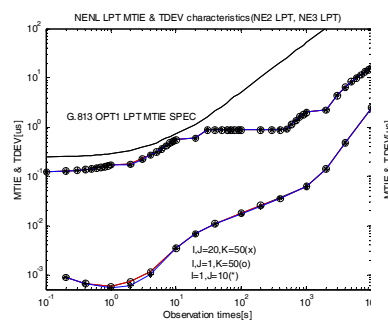

(a) NENL의 노드 특성

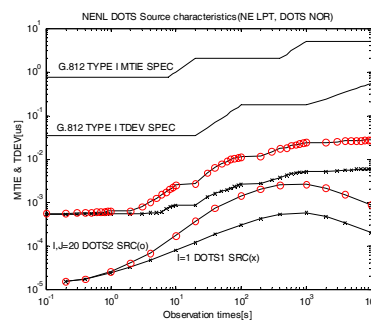

(c) NENL의 DOTS 특성

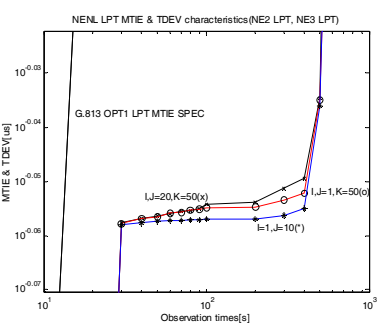

(b) (a)의 확대 그림

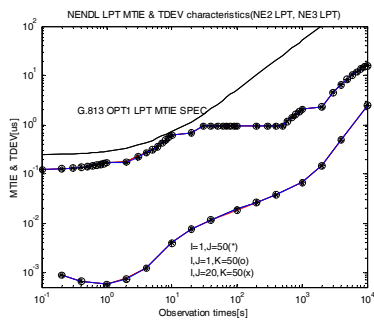

(d) NENDL의 노드 특성
(그림 6) NENL, NENDL LPT상태의 노드클럭특성

1 이고 $j$ 가 10 일 때의 $\mathrm{NE} 2 \mathrm{MTIE}($ 위 ) 특성 ('*')은 G.813 $\mathrm{LPT} \mathrm{MTIE}$ 규격(TDEV 규격은 권고하지 않음) 보다 작은 값을 가지고 있기 때문에 규격을 만족하고 있으며, $i, j$ 가 1 이고 $k$ 가 $50\left({ }^{\prime} \mathrm{O}^{\prime}\right)$ 일 때와 $i, j$ 가 20이고 $k$ 가 $50\left({ }^{\prime} \mathrm{x}^{\prime}\right)$ 일 때인 $\mathrm{NE} 3$ 의 MTIE 특성도 관련 규격을 만족하였다. 노드수가 80 일 때도 수행하였으나 역시 관련규격을 만족하였다. (그림 6)(b)는 (a)경우에서 관측시간 100 초에서 부근을 확대한 그 래프로, 노드수가 증가함에 따라 클럭특성 잡음도 증가함을 볼 수 있다. (그림 6)(c)는 NE2와 NE3에서 동기원클럭으로 사용되는 DOTS1('x')과 DOTS2('o')의 MTIE(위), TDEV (아래) 클럭 특성을 관련규격과 비교한 결과로 모두 규격을 만족하였다. NENL의 기타 경우에 대한 시뮬레이션 결과는 <표 5>에 나타나 있으며, NE2, NE3 모든 경우에서 50개 이상의 노드에서 관련 규격을 만족하였다. (그림 5)(d)는 최 종단 $\mathrm{NE}$ 와 DOTS가 LPT상태인 NENDL 경우를 나타내었 으며, $i$ 가 1 이고 $j$ 가 50 인 $\mathrm{NE} 2\left({ }^{\prime} *^{\prime}\right), i, j$ 가 1 이고 $k$ 가 $50\left({ }^{\prime} \mathrm{O}^{\prime}\right)$ 일 때와 $i, j$ 가 20 이고 $k$ 가 $50\left({ }^{\prime} \mathrm{x}^{\prime}\right)$ 일 때인 $\mathrm{NE} 3$ 모두 G.813 LPT 규격을 만족하였다. 기타 경우에 대한 시뮬레이 션 결과는 <표 $6>$ 에서와 같이 모든 경우에서 50 개 이상의 노드에서도 관련 규격을 만족하였다.

전체 전송망을 LPT상태로 적용하는 NLNL 특성은 (그림 7)에 나타나 있다. (그림 7)(a)에서 $i$ 가 1이고 $j$ 가 50인 $\mathrm{NE} 2\left({ }^{\prime} *^{\prime}\right)$ 경우와 $i, j$ 가 1 이고 $k$ 가 $50\left({ }^{\prime} \mathrm{o}^{\prime}\right), i, j$ 가 20이고 $k$ 가 $50\left({ }^{\prime} x^{\prime}\right)$ 일 때인 NE3 경우 모두에서 LPT 규격을 만족함을 볼 수 있다. (그림 7)(b)는 NE2와 NE3에서 동기원클럭으로 사용되는 $\operatorname{DOTS} 1\left({ }^{\prime} x^{\prime}\right)$ 과 $\operatorname{DOTS} 2\left({ }^{\prime} \mathrm{o}^{\prime}\right)$ 의 $\mathrm{MTIE}($ 위), TDEV (아래) 클럭 특성이지만 G.812 정상상태의 MTIE와 TDEV 규격을 관측시간 2,000 초 이상에서 모두 만족하지 못하였다. $\mathrm{NLNL}$ 의 기타 경우에 대한 시뮬레이션 결과는 <표 $7>$ 에서 와 같이 모든 경우에서 50 개 이상의 노드에서도 관련 규격
〈표 5〉NENL일 때의 노드수

\begin{tabular}{|c|c|c|c|}
\hline \multirow{2}{*}{ 형태 } & $\begin{array}{c}\text { NE1 } \\
\text { (LPT) }\end{array}$ & NE2(LPT) & NE3(LPT) \\
\hline \hline \multirow{2}{*}{ 동기원 } & \multirow{2}{*}{ PRC } & DOTS1(NOR) & DOTS2(NOR) \\
\cline { 3 - 4 } & $\mathrm{i}=1,5,10,15,20$ & $\mathrm{i}, \mathrm{j}=1,5,10,15,20$ \\
\hline 노드수 & $50 \geq$ & $50 \geq$ & $50 \geq$ \\
\hline \multicolumn{2}{|c|}{ 탠덤노드 } & NE1/DOTS1 & NE1,2/DOTS1,2 \\
\multicolumn{2}{|c|}{ 규격만족도 } & NOR 규격 만족 & NOR 규격 만족 \\
\hline
\end{tabular}

〈표 6〉NENDL일 때의 노드수

\begin{tabular}{|c|c|c|c|}
\hline 형태 & $\begin{array}{l}\mathrm{NE} 1 \\
(\mathrm{LPT})\end{array}$ & NE2(LPT) & NE3(LPT) \\
\hline \multirow{2}{*}{ 동기원 } & \multirow{2}{*}{ PRC } & DOTS1(LPT) & DOTS2(LPT) \\
\hline & & $\mathrm{i}=1,5,10,15,20$ & $\mathrm{i}, \mathrm{j}=1,5,10,15,20$ \\
\hline 노드수 & $50 \geq$ & $50 \geq$ & $50 \geq$ \\
\hline \multicolumn{2}{|c|}{$\begin{array}{l}\text { 탠덤노드 } \\
\text { 규격만족도 }\end{array}$} & $\begin{array}{l}\text { NE1 NOR, DOTS1 } \\
\text { LPT 규격 만족 }\end{array}$ & $\begin{array}{l}\text { NE1,2/DOTS1 NOR, } \\
\text { DOTS2 LPT 규격 만족 }\end{array}$ \\
\hline
\end{tabular}

〈표 7〉NLNL일 때의 노드수

\begin{tabular}{|c|c|c|c|}
\hline 형태 & $\begin{array}{c}\text { NE1 } \\
\text { (LPT) }\end{array}$ & NE2(LPT) & NE3(LPT) \\
\hline \hline 동기원 & \multirow{2}{*}{ PRC } & DOTS1(NOR) & DOTS2(NOR) \\
\cline { 2 - 4 } & $\mathrm{i}=1,5,10,15,20$ & $\mathrm{i}, \mathrm{j}=1,5,10,15,20$ \\
\hline 노드수 & $50 \geq$ & $50 \geq$ & $50 \geq$ \\
\hline \multicolumn{2}{|c|}{ 탠덤노드 } \\
\multicolumn{2}{|c|}{ 규격만족도 } & $\begin{array}{c}\text { NE1 LPT } \\
\text { 규격 만족, DOTS1 } \\
\text { NOR 규격 불만족 }\end{array}$ & $\begin{array}{c}\text { NE1,2 LPT } \\
\text { 규격 만족, DOTS1,2 NOR } \\
\text { 규격 불만족 }\end{array}$ \\
\hline
\end{tabular}

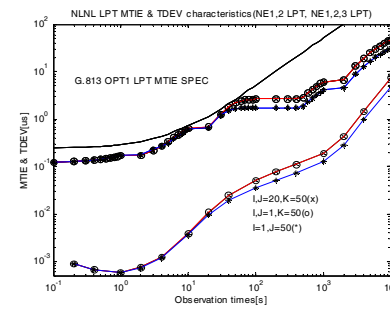

(a) NLNL의 노드 특성

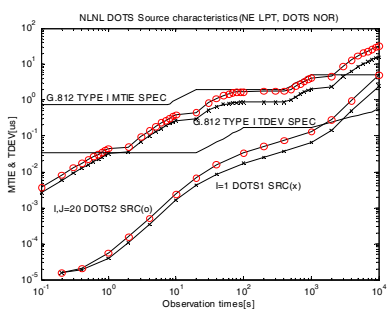

(b) NLNL의 DOTS 특성
(그림 7) NLNL LPT상태의 노드클럭특성

을 만족하였으나 DOTS 동기원은 모두 G.812 정상상태 규 격을 만족하지 못했다.

\section{5 시뮬레이션 결과분석}

정상상태에서는 3.2 절의 결과를 통해볼 때 <표 $1>$ 에서 $\mathrm{NE} 1$ 일 경우 $i, \mathrm{NE} 2$ 일 경우 $j, \mathrm{NE} 3$ 일 경우 $k$ 개의 전송망 노 드수가 모든 경우에서 80개이상 연결하여도 $\mathrm{NE}$ 와 DOTS 동기원클럭에 대한 ITU규격을 모두 만족하였다. 다시 말해 서 국내 동기망과 전송망을 구축할 때 $\mathrm{KRF}$ 를 바로 사용하 거나 혹은 DOTS1, DOTS2 동기원을 사용하더라도 80개 이 상의 노드를 병렬로 연결, 사용하여도 국제규격을 만족할 수 있는 좋은 클럭상태임을 알 수 있다. 실제적으로 80개 
이상의 노드로 망을 구성하지 않기 때문에 정상상태에서의 망구성 노드수에 대한 제약조건은 없는 것으로 판단된다.

$\mathrm{SPT}$ 상태는 3.3절의 결과를 통해볼 때 우선 <표 2>에서 $\mathrm{NE} 1, \mathrm{NE} 2, \mathrm{NE} 3$ 전송망 중에서 $\mathrm{SPT}$ 상태가 발생한 망이 존 재한다면 해당 망에서만 38 개 노드 이상에서 관련 규격을 만족하지 않았고, SPT상태가 발생하지 않는다면 노드수 제 한이 발생치 않는다. <표 3>에서 만일 동기원을 공급하는 DOTS1과 동기원을 받아 망동기를 시키는 전송망인 NE2 혹은 DOTS2와 NE3가 동시에 SPT 상태가 발생하면 전송 망의 노드수가 1 개부터 관련 규격을 만족하지 않기 때문에 이와 같은 상황이 발생하면 즉각적으로 전송망에 공급돠는 동기원을 절체해야 한다. 그리고 <표 4>에서 확률적으로 발 생할 가능성이 낮지만 만일 $\mathrm{NE} 1, \mathrm{NE} 2, \mathrm{NE} 3$ 의 전송망이 동 시에 SPT상태가 발생한다면 DOTS-NE 망그룹이 증가할수 록 38 개부터 시작해서 10 에서 최소 1 개까지 규격을 만족하 기 않는 것으로 나타나고 있어서 10 개 이하의 노드수는 실 제 망에서 사용할 수 있기 때문에 심각한 문제가 발생할 수 있다. 따라서 이와 같은 현상을 막기 위해서는 DOTS에 소 스를 공급되는 앞단의 전송망이 SPT가 발생되면 발생노드 에서 동기원을 받지말고 정상상태에서 안정되게 공급되는 다른 경로의 전송망에서 공급되는 소스로 절체해서 DOTS 에 공급되도록 해야 한다. 이를 경우에는 앞서 살펴본 <표 $2>$ 의 NENS 경우와 동일하게 항상 관련규격을 만족하는 37 개 이내의 노드수를 사용할 수 있다.

LPT상태는 3.4절의 결과를 통해볼 때 <표 5>, <표 6>, $<$ 표 7>에서 NENL, NENDL, NLNL의 경우 모두 LPT 상 태가 발생하더라도 50 개 이상에서도 LPT 규격을 만족하고 있어서 LPT상태 발생에 따른 노드수 제한은 없는 것을 나 타났다. 다시 말해서 전송망이나 DOTS가 개별적으로나 동 시에 LPT상태가 발생하더라도 LPT규격을 모두 만족하고 있어서 전송망의 노드수에는 영향을 미치지 않음을 알 수 있다. 이는 LPT규격이 SPT에 비해서 비교적 엄격하지 않 음을 알 수 있다. 다만 NE2와 NE3에서 DOTS 앞단의 전송 망인 NE1과 NE2에 LPT상태가 발생하면 DOTS의 정상상 태 클럭특성에 영향을 미치는 것으로 나타나고 있어서 이와 같은 문제점을 해결하기 위해서는 SPT 상태에서와 같이 DOTS 앞단의 전송망에 LPT상태가 발생되면 해당 전송노 드에서 소스를 받지 말고 정상상태에서 안정되게 공급되는 다른 전송망에서 공급되는 소스로의 절체를 수행해야 한다.

지금까지 세가지 클럭상태에 따른 시뮬레이션 결과를 종 합해 볼 때 순수한 클럭 관점에서, 실제 국내클럭을 사용할 경우 전송망의 노드수를 37 개 이내로 구성해야 ITU-T 관 련규격을 만족하여 안정된 $\mathrm{NG-SDH}$ 전송망과 동기망을 얻 을 수 있을 것으로 판단된다. 또한 만일 DOTS 앞단의 $\mathrm{NE}$ 전송망에서 $\mathrm{SPT}$ 이나 $\mathrm{LPT}$ 상태가 발생한다면 관련 규격을 만족하기 위해서 정상상태의 안정된 전송망에서 공급되는 소스로 신속하게 절체되어야 한다는 것을 알았다.

\section{4. 결 론}

$\mathrm{NG}-\mathrm{SDH}$ 망에서 실제 측정된 국내 클럭잡음을 이용하여 다양한 클럭상태에 따른 동기클럭 특성 연구가 지금까지 이 루어지지 않았다. 본 논문은 실제 측정된 클럭잡음을 이용 하여 적합한 $\mathrm{NE}$ 와 DOTS 클럭모델을 만들어, $\mathrm{NG-SDH}$ 망 의 다양한 클럭상태에 따른 동기클럭 성능분석과 최대 망노 드수 도출을 위한 연구를 수행하였다. 3가지 클럭상태에 따 른 시뮬레이션 결과를 종합해 볼 때 정상상태에서는 80개 노드 이상으로 구성 가능하고, SPT상태에서는 37개 이내로 구성해야 하고, LPT상태에서는 50개 이상으로 망구성이 가 능하였다. 따라서 3 가지 클럭상태를 모두 만족할 수 망구성 노드수는 37 개 이내로 구성해야 ITU-T 관련규격을 만족하 여 안정된 $\mathrm{NG}-\mathrm{SDH}$ 전송망과 동기망을 얻을 수 있음을 알 았다. 다만 DOTS 앞단의 NE 전송망에서 SPT나 LPT 상태 가 발생한다면 정상상태의 안정된 전송망에서 공급되는 소 스로 신속하게 절체해야만 관련 규격을 만족할 수 있음을 알았다. 본 논문결과는 $\mathrm{NG-SDH}$ 전송장비의 동기기능 개발 과 $\mathrm{NG}-\mathrm{SDH}$ 망설계에 설계기초 자료로 직접 활용할 수 있 으며, 또한 향후 다양한 $\mathrm{ETDM}, \mathrm{WDM}, \mathrm{OTN}$ 시스템 등에 널리 활용할 수 있을 것으로 판단된다.

\section{참 고 문 헌}

[1] Dirceu Cavendish et al., "Next Transport Services for Next Generation SONET/SDH Systems," IEEE Communications Magazine, pp.80-7, May, 2002.

[2] ITU-T G.707/Y.1322, "Network node interface for the synchronous digital hierarchy (SDH)," August 2002.

[3] ITU-T Draft Recommendation G.7041, "Generic framing procedure(GFP)," December, 2001.

[4] ITU-T Draft Recommendation G.7042, "Link capacity adjustment scheme(LCAS) for virtual concatenated signals," August, 2002.

[5] ITU-T Recommendation G.810, "Definitions and terminology for synchronization networks," Sept., 1997.

[6] ITU-T Recommendation G.811, "Timing characteristics of primary reference clock," Sept., 1997.

[7] ITU-T Recommendation G.812, "Timing requirements of slave clocks suitable for use as node clocks in synchronization networks," March, 2005.

[8] ITU-T Recommendation G.813, "Timing characteristics of SDH equipment slave clocks(SEC)," March 2003.

[9] ITU-T Recommendation G.783, "Characteristics of synchronous digital hierarchy (SDH) equipment functional blocks," 1997. 
[10] G. Garner, "Noise accumulation in synchronization reference chains," Contribution to T1 Standard Project, T1X1. 3 / 95-044, 1995.

[11] ANSI Draft T1.105.09, "Network element timing and synchronization," 1995.

[12] ANSI Revised Draft T1.101, "Synchronization interface standard," 1999

[13] 한국전기통신공사, 디지털 클럭 공급장치(DOTS) 설명서, 1988.

[14] 이창기, "동기망과 동기식 전송망에서의 동기클럭 단기안정 특 성 분석,"한국정보처리학회 논문지, 제8-C권, 제3호, pp299 -309, 2001년 6월.

[15] 이창기, "NG-SDH 망동기에 관한 연구," 한국전자통신연구원 최종연구보고서, 2004년 11월.

[16] 이창기, “동기망과 전송망에서의 동기클럭 성능분석을 위한 시 뮬레이터 개발," 한국정보처리학회 논문지, 제11-C권, 제1호, pp.123-134, 2004년 2월.
[17] 이창기, "NG-SDH 망에서 다양한 클럭상태 하에서의 동기클 럭 성능분석에 관한 연구,” 한국정보처리학회 논문지, 제 $13-\mathrm{C}$ 권, 제3호, pp303-310, 2006년 6월.

[18] 양충열, 고제수, 이창기, 김환우, "광전송플랫폼에서의 망동기 장치 구현과 광전송망에 미치는 원더의 영향분석,” 한국통신학 회 논문지, 제32권 제7호, pp.678-685, 2007년 7월.

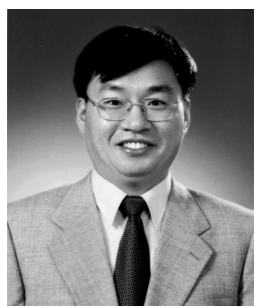

\section{이 창 기}

e-mail : cklee@uu.ac.kr 1984년 경북대학교 전자공학과(학사) 1986년 경북대학교 전자공학과(공학석사) 1998년 경북대학교 전자공학과(공학박사) 1987년 1999년 한국전자통신연구원 광통 신연구부 선임연구원

1999년 현 재 위덕대학교 정보통신공학과 부교수 관심분야: $\mathrm{OTN}, \mathrm{NG}-\mathrm{SDH}$, Network Synchronization, $\mathrm{BcN}$ 등 